\title{
Alguns Apontamentos sobre a Trajetória da Psicologia Social Comunitária no Brasil
}

\author{
Notes About The History Of Community Social \\ Psychology In Brazil
}

Algunas Notas Sobre La Trayectoria De La Psicología Social Comunitaria En Brasil
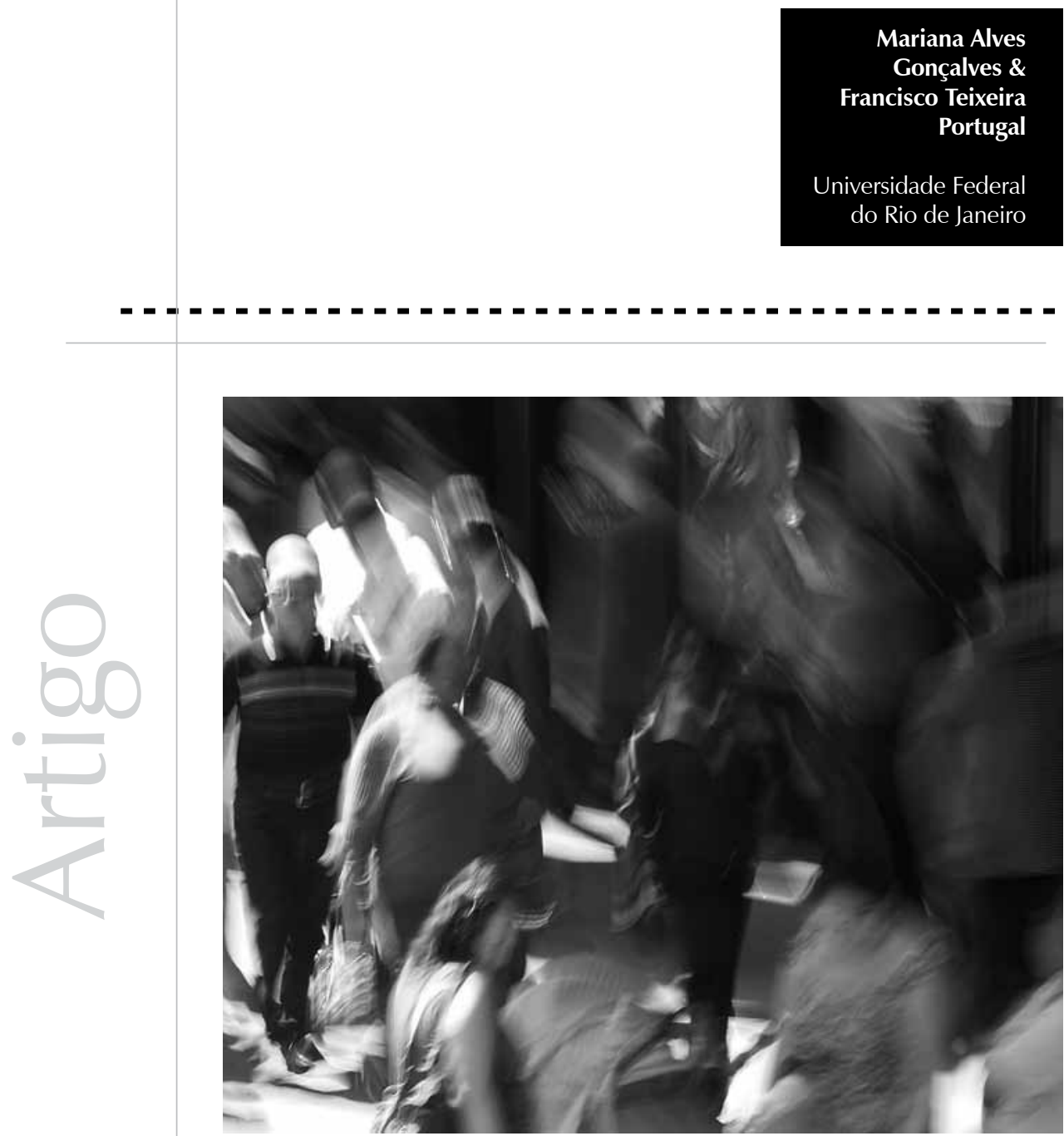
Resumo: Este artigo aborda a trajetória da Psicologia social comunitária no Brasil tomando como material privilegiado de análise os anais dos encontros nacionais da Associação Brasileira de Psicologia Social (ABRAPSO). O objetivo foi o de historiar os argumentos produzidos por autores da PSC em busca de uma identidade para a área. A análise buscou evidenciar a especificidade da PSC, os objetivos de suas intervenções e a noção de comunidade. Tomamos os anais dos encontros nacionais da ABRAPSO como fonte principal pela importância da associação na produção de dispositivos conceituais e de novas formas de atuação profissional dos psicólogos no Brasil. Concluímos o trabalho indicando a ênfase na diferença e na oposicão entre uma psicologia latino e norte-americana como recurso estratégico de afirmação identitária da área. Apontamos a importância do trabalho em comunidade para a renovação das práticas do psicólogo no Brasil e para a relativa carência de reflexão conceitual sobre a noção de comunidade.

Palavras-chave: Psicologia social-História. Psicologia comunitária. Organizações profissionais - Psicologia. Psicologia aplicada.

Abstract: This article discusses the trajectory of community social psychology in Brazil taking as primary material of analysis the annals of the national meetings of the Associação Brasileira de Psicologia Social (ABRAPSO). The goal was to reconstruct the arguments made by authors of CSP in search of an identity for the area. The analysis sought to demonstrate the specificity of the PSC, the goals of their interventions and the meanings of community. We take the annals of the national meetings of ABRAPSO as the main source for the importance of the association in the production of conceptual devices and new forms of professional practice of psychologists in Brazil. We conclude the work indicating the emphasis on difference and antithesis between Latin and North American psychology as a strategic resource for identity affirmation in the area. We point to the importance of community work for the renewal of the psychologist practices in Brazil and the relative lack of conceptual reflection on the notion of community.

Keywords: Social Psychology-History. Community psychology. Professional organizations-Psychology. Applied psychology.

Resumen: Este artículo aborda la trayectoria de la Psicología social comunitaria en el Brasil tomando como material privilegiado de análisis los anales de los encuentros nacionales de la Asociación Brasileña de Psicología Social (ABRAPSO). El objetivo fue el de historiar los argumentos producidos por autores de la PSC en busca de una identidad para el área. El análisis buscó evidenciar la especificidad de la PSC, IOS objetivos de sus intervenciones y la noción de comunidad. Tomamos los anales de los encuentros nacionales de la ABRAPSO como fuente principal por la importancia de la asociación en la producción de dispositivos conceptuales y de nuevas formas de actuación profesional de los psicólogos en el Brasil. Concluimos el trabajo indicando el énfasis en la diferencia y en la oposición entre una psicología latina y norteamericana como recurso estratégico de afirmación de identidad del área. Apuntamos la importancia del trabajo en comunidad para la renovación de las prácticas del psicólogo en el Brasil y para la relativa carencia de reflexión conceptual sobre la noción de comunidad.

Palabras clave: Psicología social-Historia. Psicología comunitaria. Organizaciones profesionales -Psicología. Psicología aplicada.

A emergência e a formação da Psicologia social comunitária (PSC) no Brasil, nos últimos 50 anos, foram marcadas, por um lado, pela contraposição aos dispositivos conceituais, aos locais de trabalhado consagrados e às práticas da psicologia social norte-americana ao longo do século XX e, por outro, pela inserção da noção de comunidade em seu conjunto de princípios. Nosso objetivo consiste em historiar os argumentos que buscaram fornecer uma identidade para a PSC e, nesse exercício analítico, indicar suas contribuições para a reflexão das práticas dos psicólogos. A análise tomou como material primário os anais dos encontros nacionais da Associação Brasileira de Psicologia Social (ABRAPSO) pela sua importância para a renovação da Psicologia social no Brasil nas três últimas décadas.

Nosso propósito não foi investigar a emergência do saber a partir de agenciamentos econômicos, políticos, acadêmicos e institucionais, mas apresentar como a disciplina se apresenta e, ao analisar o discurso produzido com o nome PSC, refletir sobre a prática profissional. Nesse sentido, discorreremos tanto sobre a emergência dessa disciplina pelo que tem sido narrado por seus autores quanto sobre o que foi por ela gerado. 
A ABRAPSO foi fundada em 1980 a partir de discussões de pesquisadores latinoamericanos que defenderam a formulação de dispositivos conceituais e metodológicos afeitos às características diferenciais desses países (Nascimento, 2001, Bock \& Furtado, 2006; Jacó-Vilela, 2011; Associação Brasileira de Psicologia Social - ABRAPSO, 2012), e tem se constituído como importante agente na construção de uma perspectiva inovadora da Psicologia no Brasil (Bock \& Furtado, 2006). Nesse sentido, o sítio da associação enfatiza o "intercâmbio e posicionamento crítico frente a perspectivas naturalizantes e a-históricas de produção de conhecimento e intervenção política em nossa sociedade" (ABRAPSO, 2012). Ao longo de seus 32 anos, a ABRAPSO realizou 16 encontros nacionais com grande número de participantes e significativa produção textual. Em decorrência da extensão do material, escolhemos trabalhar com os números pares dos anais existentes, o que totalizou seis anais. Foram selecionados os documentos dos seguintes encontros nacionais: II, IV, VI, VIII, XI e XIV Encontro Nacional da ABRAPSO, realizados, respectivamente, em 1986, 1988, 1991, 1995, 2003 e 2007. Os anais do $X$ Encontro Nacional da ABRAPSO, de 1999, não estão disponíveis para análise.

É importante alertar que a pesquisa não busca oferecer elementos que sirvam para delimitar o que é e o que não é Psicologia social comunitária. Aqui não se fala do lugar de quem pretende afirmar o campo ou ratificar simplesmente suas posições. Não nos interessa, portanto, alcançar nenhuma espécie de unidade, identidade e/ou legitimidade da PSC. Concebendo essa busca de unificação e os produtos por ela gerados como regimes de verdade historicamente instituídos, pretendemos problematizá-la (Barros, 2007, p. 128).

\section{Aspectos históricos do campo}

A partir da década de 70, a Psicologia passa por um momento de transformações significativas decorrentes, em parte, dos questionamentos que envolvem a relevância da Psicologia social (Lane \& Codo, 1984; Jacques, Strey, Bernardes, Guareschi, Carlos, \& Fonseca, 2003; Carvalho \& Souza, 2010). Sob os auspícios dessa crise, ou por sua convocação, houve a constituição de um conjunto de problematizações relacionadas com o surgimento de diversas propostas para a disciplina no Brasil e na América Latina. Entre as questões levantadas naquele momento, estão a falta de relevância social das pesquisas em Psicologia social, a reivindicação de que se constituísse um rumo próprio para a disciplina a partir da realidade social, econômica e política latino-americana e o compromisso com a transformação social (Bock, Gonçalves, \& Furtado, 2007; Carvalho \& Souza, 2010).

A Psicologia da libertação, a Psicologia social comunitária, a Psicologia sociohistórica e a Psicologia política surgiram envolvidas com esses questionamentos e elaboraram argumentos para modificar a psicologia social latino-americana. O que atualmente chamamos de PSC surgiu eminentemente de práticas realizadas em favelas e comunidades, quando isso ainda era uma novidade para a disciplina. A trajetória da PSC está, portanto, atrelada a esse momento de críticas à Psicologia social caracterizada até então por um viés cognitivista e experimental, e, como todo discurso de crise, a um movimento de reformulação das práticas vigentes. Houve, portanto, uma mudança de direção na psicologia brasileira, em que a PSC e a Psicologia social crítica tiveram participação intensa. Foi então que a Psicologia reivindicou a tarefa de atuar de uma forma diferente nas transformações sociais, não só atenta às questões das maiorias populares e evitando 
A aproximação da Psicologia às camadas populares e a abertura dos seus campos de atuação foi favorecida, a partir da década de 90 pela abertura de campo de trabalho nas instituições públicas de saúde que atendiam, sob o primado das ações territoriais, essas populações menos favorecidas economicamente (Yamamoto \& Oliveira, 2010). o recurso às intervenções dos psicólogos especialistas mas também responsável por promover mudanças na realidade dessa população.

O surgimento da PSC pode ser considerado uma tentativa de responder a essas críticas e de propor mudanças para a psicologia social latino-americana. Assim, novas diretrizes da disciplina foram instituídas, a saber, deselitizar a Psicologia (Freitas, 1988, 1996, 2010; Nascimento, 2001), aproximar-se da realidade concreta da população (MartínBaró, 1996, 2009) e afastar-se dos lugares tradicionais de trabalho (Freitas, 1988, 1996, 2010; Nascimento, 2001; Carvalho \& Souza, 2010). Autores variados (Lane, 1996; Campos, 1996; Freitas, 1988, 1996; Góis, 2005; Montero, 2011; Martín-Baró, 1996, 2009) indicam a estratégia de aproximação dessa área a alguns setores da população antes negligenciados pela Psicologia, e de realização de algum tipo de intervenção na comunidade como aspectos comuns ao início da trajetória da Psicologia social comunitária no Brasil, mesmo que os referenciais teóricos e os objetivos não estivessem bem definidos.

É importante lembrar que essa aproximação da Psicologia aos setores denominados menos favorecidos ou populares também se concretizou a partir do final da década de 80, com o processo de redemocratização do País, a promulgação da nova Constituição e a consolidação de um conjunto de políticas sociais, principalmente no setor de saúde, e com a organização do Sistema Único de Saúde (SUS). A aproximação da Psicologia às camadas populares e a abertura dos seus campos de atuação foi favorecida, a partir da década de 90, pela abertura de campo de trabalho nas instituições públicas de saúde que atendiam, sob o primado das ações territoriais, essas populações menos favorecidas economicamente (Yamamoto \& Oliveira, 2010).

\section{A discussão histórica em torno da PSC}

A história da PSC é comumente narrada em suas principais referências e livrostexto (Montero, 2011; Góis, 2005; Álvaro \& Garrido, 2006; Nepomuceno, Ximenes, Cidade, Mendonça, \& Soares, 2008) a partir de uma divisão primordial entre o seu surgimento e suas influências na América Latina e nos Estados Unidos. A ênfase nessa distinção não se restringiu à PSC, mas esteve presente nos argumentos da renovação da Psicologia social entre nós.

Nos territórios norte-americano e europeu, o surgimento da Psicologia comunitária ocorreu em meados da década de 60 , relacionado aos movimentos sociais comunitários, em especial os de saúde mental. A conferência de Swampscott, realizada nos EUA, em 1965, envolvida com a constituição dos serviços de saúde mental de base comunitária e com as críticas às intervenções exclusivamente médicas e hospitalocêntricas nos casos de doença mental, tem sido apontada como um marco para a constituição da disciplina (Góis, 2005; Álvaro \& Garrido, 2006). Inspirados nos pressupostos da psiquiatria preventiva, esses movimentos tinham como objetivo não somente tratar as doenças mentais mas também preveni-las. As intervenções, antes limitadas aos indivíduos, foram ampliadas para seu entorno - também chamado comunidade - concebido como fonte dos problemas mentais e, ao mesmo tempo, como agente potencialmente terapêutico.

A psiquiatria preventiva nasceu nos Estados Unidos, no bojo das transformações das práticas psiquiátricas decorrentes da constatação feita em 1955 pelo governo central das péssimas condições de assistência psiquiátrica no país. Sua pretensão foi intervir nas causas ou na origem das doenças mentais a fim de prevenir a doença mental e promover a 
saúde mental em consonância com o Decreto Federal de 1963, que redirecionava os objetivos da psiquiatria incluindo a "redução da doença mental nas comunidades" como uma de suas finalidades. A estratégia preventiva calca sua ação sobre as doenças mentais na crença de que elas podem ser prevenidas ou detectadas precocemente por meio de uma intervenção social nos espaços potencialmente patogênicos com o intuito de buscar suspeitos. A partir da articulação com as teorias sociológicas e antropológicas, Caplan (1980) concebe a doença mental como desadaptação ou desvio, o que contribuiu para pavimentar o caminho para disseminar tanto a ação psiquiátrica quanto a investigação sobre a produção da doença para todos os recantos da cidade e para todas as ações aí realizadas (Amarante, 1995, pp. 36-38).

É notória, portanto, a dificuldade em distinguir historicamente as origens do que se chama de psicologia comunitária norteamericana do movimento acima descrito e caracterizado como psiquiatria preventiva. Ambos aconteceram na mesma dimensão espaço-temporal, e são considerados como a terceira revolução na saúde mental, quando comparados aos feitos de Pinel e de Freud (Gallindo, 1981; Amarante, 1995). Além disso, a importância desse projeto da psiquiatria preventiva foi ter se centrado na intervenção social como princípio de identificação precoce de candidatos a tratamento psiquiátrico, e, ao mesmo tempo, ter sido pautada pela crença de que, ao intervir no território, seria possível prevenir doenças mentais e, sobretudo, promover saúde mental. Constata-se aqui o deslocamento e o alargamento do objeto, que passa da doença para a saúde, provocando também uma ampliação da intervenção, que desliza do indivíduo para a coletividade, compreendida como meio ambiente ou comunidade.
Ao traçar o percurso da Psicologia comunitária na América Latina, variados autores (Montero, 2011; Góis, 2005, 2008; Freitas, 1996, 2008; Lane, 1996; Campos, 1996; Bomfim \& Brandão, 1999; Álvaro \& Garrido, 2006; Nascimento, 2001) enfatizaram sua vinculação com a Psicologia social e sua contribuição para o redirecionamento da Psicologia, que voltava sua atenção para os graves problemas socioeconômicos da região buscando superá-los e, dessa forma, inovar seu leque de atuação. O surgimento da Psicologia comunitária na América Latina tem sido relacionado, também, à Psicologia social crítica, à teologia da libertação e à educação popular (Góis, 2005; Freitas, 1996).

Ao longo da década 70, alguns psicólogos sociais começaram a se aliar a movimentos comunitários que surgiam no Brasil, como as Comunidades Eclesiais de Base e os movimentos na área de saúde mental, em busca de melhores condições de vida para a população (Bomfim, 1989), fornecendo um índice do envolvimento dos psicólogos com as questões sociais.

Ao descrever em que cenário ocorria o processo de transição democrática na realidade brasileira após o período marcado por repressões políticas e culturais de uma ditadura militar e também por um processo, desde a década de 60, de pauperização da população, Yamamoto e Oliveira afirmaram que, em 1980, “52\% dos domicílios e $60 \%$ das famílias se encontravam abaixo da linha de pobreza, tomando por parâmetro o limite de três salários mínimos. Em ordem de grandeza, a pobreza atingia 17 milhões de famílias e 68 milhões de pessoas" (2010, p.10). Com o fim da ditadura militar, as discussões sobre os trabalhos realizados em comunidades foram objeto de mais atenção, principalmente por ter sido essa uma atividade não remunerada, clandestina e voluntária. Nesse momento, o termo Psicologia comunitária passou a ser adotado por profissionais em debates e reflexões (D'Amorin, 1980; Freitas, 1996). 


\section{Discutindo os anais da ABRAPSO}

Ao longo dessa pesquisa, deparamo-nos com documentos em formatos completamente distintos, e pareceu-nos importante destacar esta heterogeneidade.

Os anais do II, IV e VI Encontros têm o formato de revista com artigos de autores selecionados, e constituem, respectivamente, os volumes do periódico da ABRAPSO Psicologia \& Sociedade indicados a seguir: ano II, número 3, 1987; ano IV, número 7 , 1989, e ano VII, número 10, 1992. Os anais dos VIII, XII e XIV Encontros Nacionais foram publicados no formato caderno de resumos. Por fim, os anais do XIV Encontro apresentam outra configuração, tendo sido publicados também no site da associação com resumos estendidos (com cerca de 1500 palavras).

A quantidade de trabalhos também varia bastante. Os anais do VIII Encontro Nacional de 1995 apresentam somente quatro resumos relacionados ao campo da Psicologia social comunitária, enquanto, em contraste, foram levantados 84 resumos para análise nos anais do XII Encontro Nacional ocorrido em 2003. Essa diferença deriva do crescimento significativo dos encontros nacionais da ABRAPSO, assim como do aumento de sua representatividade no campo da Psicologia. Devemos ainda creditar parcialmente tal acréscimo ao contínuo aumento no número de estudantes e profissionais de Psicologia no País nas últimas décadas.

Há uma diferença importante entre os anais no que diz respeito às regiões a que esses trabalhos estiveram vinculados ao longo desses anos. Os primeiros documentos analisados correspondentes aos II, IV, VI e VIII Encontros estavam vinculados somente à Região Sul-Sudeste do País, em sua maioria, aos Estados de São Paulo e Minas Gerais, mas também encontramos trabalhos do Paraná e do Espírito Santo. Já a partir 2003, no XII
Encontro, há uma ampliação significativa na variedade de Estados presentes, o que acontece também em 2007, com maior participação do eixo norte-nordeste do País.

\section{(In)definições do campo e a especificidade do trabalho do psicólogo comunitário}

Visamos, neste trabalho, a expor o modo pelo qual representantes da PSC definiram seu próprio campo de atuação, seu escopo e seus limites. A expectativa de fornecer unidade ao campo tem sido um horizonte para seus representantes. O aumento do número de publicações já foi argumento para evidenciar a proximidade "de uma concepção geral de Psicologia comunitária, de sua especificidade" (Góis, 2005, p. 32). Sabemos que o que se chama hoje PSC começou com uma tentativa de aproximar a Psicologia de alguns setores da população, ainda sem objetivos e métodos bem definidos. A tarefa de dar uma forma ao que foi produzido tem sido fruto de um esforço identitário da PSC. Dessa forma, torna-se mais fácil distinguir quem pertence ou não a ela, quem está autorizado a falar e a responder suas questões, quais são, afinal, as suas práticas, orientações e métodos. Essa estratégia da PSC tem diversos efeitos e responde a alguns objetivos, como, por exemplo, oferecer especificidade ao campo e tornar aqueles que pertencem a ele especialistas.

Para Góis, a Psicologia comunitária é o

ramo da Psicologia social que estuda os processos, formações e propriedades psicológicas decorrentes da vida comunitária, seu sistema de relações e representações, identidade, níveis de consciência, atitudes, hábitos, expectativas, sentimentos e valores, a identificação e a pertinência dos membros aos grupos comunitários e à própria comunidade, na perspectiva do desenvolvimento da consciência dos membros como sujeitos históricos e comunitários. Seu campo 
de atuação é a comunidade, espaço geográfico, social e econômico, significativo e básico da vida em sociedade (1989, p. 100)

Dessa forma, segundo esse autor, a Psicologia comunitária não é uma extensão da clínica, não é uma Psicologia na comunidade, e nem uma tecnologia social. Seu objeto central seria, então, "o reflexo psíquico da vida comunitária (...) no psiquismo de seus membros e a potencialização da consciência a partir das condições de vida da comunidade" (Góis, 1990, p. 100). A questão central da Psicologia comunitária é "o desenvolvimento do indivíduo enquanto sujeito histórico, social e comunitário (...)", (Góis, 1990, p. 100), e não a relação entre saúde e doença ou prevenção e tratamento.

Freitas (1996) propõe uma discussão semelhante quando discorre sobre os termos adotados nos diferentes momentos da trajetória da PSC, contextualizando as teorias e as práticas a que estavam relacionadas. Inicialmente, o termo trabalhos em comunidade, usado nas décadas de 40 e 50, traduzia trabalhos comunitários de cunho paternalista e assistencialista realizados junto aos setores mais desfavorecidos do País.

A expressão psicologia da comunidade começou a ser usada nos anos 90, com uma ampliação dos trabalhos dos profissionais de Psicologia a diversos setores da população adotando diferentes práticas e referenciais teóricos e traduziu uma inserção da Psicologia em algumas instituições, com o objetivo de democratizar e de aumentar a oferta de serviços para a população em geral. Nessas instituições, o que aconteceu foi um atrelamento da profissão à área de saúde, já que os psicólogos deviam ser trabalhadores sociais dentro dessa área, muitas vezes respondendo aos problemas da saúde coletiva.
A Psicologia comunitária, ou Psicologia social comunitária, para os latino-americanos, apresenta mudanças significativas em relação aos modelos anteriores. Para a Psicologia (social) comunitária, o homem deve ser compreendido como sociohistoricamente construído. Ela "utiliza-se do enquadre teórico da Psicologia social, privilegiando o trabalho com os grupos, colaborando para a formação da consciência crítica e para a construção de uma identidade social e individual, orientada por preceitos eticamente humanos" (Freitas, 1996).

Nos anais pesquisados, percebe-se uma diferença no que diz respeito à presença de reflexões sobre seu próprio campo. Enquanto nos anais do IV Encontro de 1988 todos os trabalhos relacionados ao campo da Psicologia social comunitária apresentam discussões sobre seu próprio campo, nos anais do VI Encontro, não há nem menção à expressão Psicologia social comunitária, não há uma identificação dos trabalhos com o campo, apesar de estarem no eixo denominado Psicologia comunitária.

A partir dos anais do IV Encontro Nacional, a análise dos textos indica que a Psicologia comunitária tem atuado junto a sujeitos sociais concretos nas áreas de saúde, saneamento e urbanização das comunidades carentes. As intervenções têm sido realizadas com associação de moradores, grupo de mulheres, grupo de jovens, grupo de idosos, centros de cultura, lazer, etc, caracterizandose, portanto, como um trabalho realizado junto aos movimentos sociais com vistas ao cooperativismo e à autonomia das comunidades. Nesse tipo de trabalho, o psicólogo comunitário deve estar preparado para lidar com os problemas que afligem as comunidades, como poluição, ausência de infraestrutura de saneamento, ausência de áreas de lazer, precariedade dos meios de transporte e trânsito congestionado. É nesse contexto que surgiu o entendimento de que 
“o trabalho do psicólogo comunitário é um trabalho psicossocial dirigido à melhoria da qualidade de vida" (Bomfim, 1989, p. 123).

Nesse sentido, a atuação dos psicólogos da PSC envolveu o fortalecimento de lideranças comunitárias, a assessoria a associações de moradores e o enfrentamento da contradição decorrente da observação de que as mobilizações comunitárias surgem por demandas concretas que, quando atendidas, tendem a desmobilizar os grupos. Naquele momento, entretanto, Bomfim sinalizou a manutenção de uma ação clínica nas comunidades que não trouxe nenhuma novidade para a Psicologia, ainda que tenha ampliado seu campo de atuação.

As reflexões sobre o escopo da PSC levaram Andery a responder à questão "o que vem a ser Psicologia comunitária ou Psicologia na comunidade?" das seguintes formas:

(...) Prática profissional marcada pela instrumentalização de conhecimentos e técnicas psicológicas aplicados à melhoria da qualidade de vida de indivíduos e grupos distribuídos nas aglomerações urbanas das grandes cidades: quarteirões, bairros, prédios coletivos, favelas, assim como nas escolas e centros públicos de saúde (1989, p. 125 , grifo nosso)

(...) Um movimento da Psicologia atual de paulatino distanciamento de seu 'locus' tradicional: a sala de experimentos, a sala escolar de discussões puramente acadêmicas, a ante-sala da gerência executiva das empresas industriais, o consultório particular centrado apenas no atendimento clínico individual (1989, p. 126)

O trabalho da Psicologia nas comunidades foi "propiciar o desenvolvimento de relações comunitárias" no que tange aos grupos populacionais e "ao nível do desenvolvimento de teorias psicológicas que avancem no sentido da compreensão e transformação do Homem, aqui concebido como manifestação de uma totalidade histórico-social" (Lastória,
1988, p. 143). Assim, cabe ao psicólogo comunitário inserir-se nos movimentos reivindicatórios "preocupando-se com questões relativas ao desenvolvimento dos grupos e também com as problemáticas existenciais dos participantes" (Lastória, 1988, p. 144).

Vimos que o psicólogo, em suas intervenções em comunidades, deve lidar com saneamento, alimentação, condições de trabalho e poluição, ou seja, deve tratar dos problemas que afligem essa população. É sua função direcionar seu trabalho ou aplicar as técnicas profissionais disponíveis para melhorar a qualidade de vida dessas pessoas. O termo qualidade de vida distribuiu-se por grande parte das definições em Psicologia social comunitária e configurou-se como um dos grandes objetivos do psicólogo comunitário.

Em 1988, nos anais do IV Encontro, a preocupação de Andery em relação à perda de especificidade do trabalho do psicólogo na comunidade se manifesta

por privilegiar, na comunidade, ações
de relevância social ou reivindicações
de melhoria de vida, e, por propor um
trabalho psico-educativo que leva ao
desenvolvimento da consciência social das
pessoas, não estaria o psicólogo se afastando
da Psicologia e adentrando um outro terreno
da política e da ação social? Nessa linha de
atuação, o psicólogo não se transformaria
num assistente social ou animador político,
perdendo as especificidades de sua
profissão? (1989, p. 133)

Para Arendt (1997), ao se constituir em meio à interdisciplinaridade, a Psicologia comunitária perde seus referenciais próprios, ou seja, ao se aproximar da História, da Antropologia, da Sociologia, da educação, do político, a Psicologia acaba por fazer o papel destes e perde seu objeto; perde, portanto, sua especificidade. Houve, então, uma busca pelo caráter propriamente psicológico do trabalho do psicólogo comunitário, para 
que sua intervenção pudesse se diferenciar das outras disciplinas das ciências humanas e sociais. Parte dessa demanda deriva de uma exigência acadêmica e de uma análise epistemológica conservadora, em que a inovação deve prestar contas ao instituído, pois a História nos informa que o objeto da Psicologia é, segundo Arendt,

(...) o estudo dos processos cognitivos, dos processos de aprendizagem, dos sistemas afetivos e emocionais dos seres humanos, das relações interpessoais e grupais que eles estabelecem; olhar psicológico seria o olhar fundado nas teorias que sustentam a cognição humana, a aprendizagem, a emoção, entre outros processos que configuram o comportamento humano (1997, p. 4)

A questão da especificidade é motivo de discussões variadas. A pergunta "qual é exatamente o papel do psicólogo quando inserido nesse novo contexto de atuação?" surge principalmente quando a prática do psicólogo se desvincula dos lugares consagrados de atuação - a clínica, a escola e as organizações onde, supostamente, suas tarefas já estão muito bem codificadas e delimitadas. Em geral, nesses casos, o papel exercido pelos profissionais não é motivo de maiores problematizações. O psicólogo comunitário, entretanto, se aventurava em um campo novo, ainda pouco consolidado, motivo pelo qual as questões em relação às possibilidades e aos limites de sua atuação ganharam novo alento e marcaram historicamente as produções da PSC. O reiterado questionamento sobre o fazer do psicólogo inserido em práticas comunitárias, identificado aqui desde a década de 80 , foi aspecto relevante para a institucionalização da disciplina ao longo das últimas décadas. A pergunta que surgiu diante do embaraço de não ter métodos, teorias e orientações muito bem definidas culminou na consolidação de um campo que, hoje, se apresenta instituído por um extenso arcabouço conceitual e metodológico presente na maioria de suas publicações.
Tanto nos anais do XII Encontro como nos anais do XIV Encontro, algumas discussões do campo continuam presentes. Assim, a PSC, na avaliação de Freitas (2003), tem se aproximado das políticas públicas, tem enfatizado o desenvolvimento comunitário, a formação técnico-política de agentes sociais e, além disso, tem contribuído para implementar ações de conscientização, de formação da identidade e de fortalecimento de sentimentos de pertencimento ao grupo e à comunidade. Mello e Souza (2003), por seu turno, indica que "a Psicologia comunitária no Brasil tem uma tradição de privilegiar os anseios, aspirações e perspectivas das comunidades, valorizando a cultura local e a participação de todos no processo de desenvolvimento local".

Em 2007, Marcos Vieira Silva, na mesa formada por Cecília de Mello e Souza e Jorge Castellá Sarriera, representantes do grupo de trabalho de Psicologia social comunitária da Associação Nacional de Pós-graduação e Pesquisa em Psicologia (ANPEPP) e da Associação Brasileira de Psicologia Social Comunitária (ABPSC), refletindo sobre o estado das práticas psicológicas em comunidades, fez a seguinte afirmação:

Surgindo como uma sub-área ou como um campo de práticas em Psicologia social, a Psicologia comunitária no Brasil e na América Latina traz a marca da busca pela transformação social, pela liberdade de expressão, pela emancipação da subjetividade, pela perspectiva interdisciplinar nas suas reflexões e práticas, pela luta em prol da participação política individual e coletiva, pelo acesso da população a serviços públicos de qualidade em termos de educação, saúde, saneamento básico, meio ambiente e condições dignas de moradia e trabalho. Se considerarmos a importância de tais temas para a produção da autoestima, da saúde mental, estaremos compreendendo a pertinência da Psicologia comunitária para a Psicologia como um todo $(2007$, p. 84$)$ 
A princípio, podemos observar pontos de convergência nas definições apresentadas relacionados à noção qualidade de vida e ao alargamento dos campos tradicionais da Psicologia por meio da PSC. Percebemos também que as tentativas de definir o que faz um psicólogo comunitário esbarram em pontos aparentemente dicotômicos. Afinal, ora é tarefa do profissional que atua em comunidades trabalhar com questões, digamos, mais concretas, objetivas, que dizem respeito ao saneamento, à alimentação, à infraestrutura, à criação de comissões para reivindicar transporte, água, luz, esgoto, escola; ora, ele precisa trabalhar com a afetividade, a identidade, a solidariedade, o bem-estar, a autoestima, com os problemas existenciais, ou seja, com as questões mais pessoais. Ainda que afetividade e bem-estar estejam diretamente envolvidos com alimentação e saneamento, os relatos presentes nos anais revelam uma oposição entre as dimensões coletiva e individual e, dessa forma, atribuem ao psicólogo comunitário a tarefa de elaborar frentes de trabalho que deem conta dessas duas dimensões de forma diferenciada.

\section{Objetivos das intervenções}

Ao longo da pesquisa, percebemos que a maior parte das intervenções começa com uma espécie de diagnóstico da comunidade ou de levantamento de dados ou das necessidades da população, realizados, em geral, de forma participativa. Isso se torna mais evidente nos anais mais recentes, relativos aos encontros nacionais de 2003 e 2007.

Nos relatos do IV Encontro, há duas descrições de intervenções em comunidades. A primeira descrição, do grupo do Departamento de Psicologia Social da PUC-SP, refere-se ao trabalho realizado em um bairro da periferia da cidade de Osasco, São Paulo, com duas frentes de atendimento: uma clínica e outra psicoeducativa. Na perspectiva clínica, "a orientação era a de aliviar os sintomas e clarear a problemática social subjacente, no sentido de agrupar essas pessoas nas reivindicações sociais (...)" (Andery, 1989, p. 131). Na frente psicoeducativa, foram realizados trabalhos com grupos de adolescentes (atividades de expressão corporal, discussão de problemas ligados à sexualidade, orientação ocupacional) e clube de mães (luta por uma creche no bairro). A segunda descrição diz respeito à intervenção iniciada com um levantamento de dados da população por meio de entrevistas informais e de observação participante, com o intuito de elaborar uma caracterização do território. O trabalho consistia em fazer reuniões na casa de um dos moradores com o objetivo de criar comissões de moradores para reivindicar transporte, água, luz, esgoto, escola. Dois grandes objetivos das intervenções comunitárias ficam explícitos: a conscientização social e a promoção da autonomia.

Os anais do VI Encontro (ABRAPSO, 1990/1991) contam, apenas, com dois trabalhos vinculados ao eixo Psicologia comunitária. Um deles descreve uma experiência realizada por pesquisadores da Universidade Federal do Rio de Janeiro, de implantação de um projeto de animação cultural comunitária no sul mato-grossense que visava ao desenvolvimento cultural e que se situava na discussão do impasse entre crescimento econômico e preservação ecológica e cultural da comunidade alvo da intervenção. O outro relato, vinculado à Fundação de Ensino Superior de São João Del Rei e a uma associação de assistência ao menor, consistia em uma pesquisa que buscava compreender o menino carente por meio da estruturação de sua identidade social.

Em 1995, nos anais do VIII Encontro (ABRAPSO, 1995), foram quatro os trabalhos 
relacionados à Psicologia social comunitária. Dois deles, vinculados à questão da infância, da implantação do Estatuto da Criança e do Adolescente (ECA) e dos centros de defesa dessa população, objetivavam a melhoria de suas condições de vida. Outro trabalho teve o objetivo de orientar e conscientizar a população sobre aspectos biopsicossociais do homem, e consistiu em um trabalho de prevenção em saúde mental. Por último, há a descrição de uma pesquisa relativa às perspectivas de estudantes de Psicologia sobre suas possibilidades práticas em comunidades.

Chegando aos anais de 2003 e 2007, XII (ABRAPSO, 2003) e XIV Encontros (ABRAPSO, 2007), temos um grande número de trabalhos, e, por sua vez, uma extensa lista dos objetivos que encontramos referentes às atuações do psicólogo em comunidades. Em geral, o que já foi relatado sobre a atuação profissional do psicólogo comunitário nos anais anteriores repete-se nesses dois. A questão do levantamento de demandas e necessidades com a comunidade a fim de planejar a intervenção, os objetivos de conscientização e de melhoria da qualidade de vida, o trabalho com grupos, as intervenções junto a lideranças comunitárias ou instituições (diversas) que atuam em comunidades, a prevenção em saúde mental, a discussão sobre questões culturais e ambientais (esta última muito mais presente), o vínculo com a saúde pública - agora no formato do Programa de Saúde da Família - são temas recorrentes. Nos dois últimos anais, há a rarefação da discussão sobre higiene, e poucos relatos abordam a prestação de serviços clínicos propriamente ditos, apesar de, muitas vezes, podermos identificar que os objetivos das intervenções se parecem bastante com os objetivos de um atendimento clínico stricto sensu. Nesse sentido, indicamos a presença dos seguintes objetivos entre os trabalhos: oferecer espaços de escuta para anseios, dificuldades e desejos, construir espaços de compartilhamento de experiências subjetivas, dar significado a conflitos internos, resgatar a auto-estima (pois a baixa autoestima dificulta a postura crítica e transformadora), promover o desenvolvimento pessoal e o das relações familiares, fortalecer as relações interpessoais e o vínculo familiar, interpretar comportamentos e expressões corporais, promover e resgatar valores e fortalecer a identidade e o sentimento de pertencer à comunidade.

Houve, nesses anais, uma proliferação dos objetivos que constituem a extensa lista: desenvolver/promover autonomia, independência e protagonismo, promover saúde mental e valores como solidariedade, ajuda mútua e cooperação, resgatar/promover cidadania e participação, conscientizar a população, realizar transformação social, auxiliar os grupos a repensarem ou a construírem sua identidade, fortalecer o vínculo grupal, promover autogestão, desenvolver ações de promoção da saúde, realizar ações de desenvolvimento local e de valorização cultural, fortalecer os laços sociais, prevenir a violência, formar lideranças comunitárias, despertar a visão crítica, promover o empoderamento individual e coletivo e promover a adoção de estilos de vida saudáveis.

A discussão a respeito da apatia/passividade em oposição à participação/atividade parece permear a maioria dos trabalhos pesquisados nos anais. Os relatos apontam frequentemente a não participação das pessoas nas decisões em comunidade e, por conseguinte, uma característica dessa população consistiria em apresentar uma postura passiva diante de sua realidade ou apatia diante das questões que Ihes são colocadas. Logo, um dos objetivos dos projetos de intervenção da Psicologia tem sido incentivar a participação, fazer com que as pessoas se tornem sujeitos ativos diante dos problemas que as acometem. Há um discurso de que o sucesso da intervenção pode ser auferido no momento 
em que a comunidade alcança uma postura ativa na resolução de seus problemas. O trabalho do psicólogo comunitário seria o de promover o deslocamento de uma posição de comodidade e alienação para uma outra de atividade e conscientização. $\mathrm{O}$ ideal, portanto, seria tornar os membros da comunidade responsáveis pela transformação de sua realidade.

\section{O conceito de comunidade}

Esse conceito é essencial para aqueles que se propõem estudar as aproximações entre a Psicologia e a comunidade. Nesse sentido, Bomfim (1989, p. 119) atribui às comunidades "carentes, periféricas e desprivilegiadas" o papel de disparador do trabalho comunitário no Brasil, embora o psicólogo comunitário também possa dirigir suas intervenções para as "comunidades de nível sócio-econômico mais elevado", desenvolvendo trabalhos relacionados a questões ecológicas, por exemplo (Bomfim \& Mata Machado, 1988).

O conceito de comunidade raramente figurava na história das ideias psicológicas até os anos 70, quando a Psicologia social começou a se tornar também comunitária (Sawaia, 2007). Até esse momento, a noção comunidade constava dos referenciais teóricos em Psicologia para designar essa instância intermediária entre o indivíduo e a sociedade. A consolidação do conceito não se restringiu à Psicologia social, mas envolveu grande parte das ciências humanas e sociais, especialmente das práticas em saúde mental. Afinal, a descoberta da noção de comunidade fez parte de um amplo movimento de "avaliação crítica do papel social das ciências e, por conseguinte, do paradigma da neutralidade científica, desencadeado nos anos 60 e culminando nas décadas de 70 e 80 (...)" (Sawaia, 2007, p. 35).

Góis (1989) entende que o espaço físicosocial é um ponto fundamental nessa definição. Para a constituição de uma comunidade, é necessário que o grupo viva em uma área geográfica comum e que se constitua uma trama de relações nas quais os membros tenham a mesma tradição e os mesmos interesses. A ideia de comunidade deve sempre se diferenciar da ideia de sociedade devido as suas particularidades, pois esta última implica a noção de um território delimitado, onde se possa ter vizinhança, intimidade, cotidianeidade, proximidade e identificação. Entre os fatores que caracterizam uma comunidade, estão: "sentimento de pertença, participação na mesma cultura e vinculação a um território comum", e ainda, "espaço de moradia e de convivência direta e duradoura, igual nível socioeconômico dos moradores, laço histórico comum, mesmas necessidades e problemas sociais e um sistema próprio de representações sociais" (Góis, 2005, p. 61).

Na tentativa de rastrear discussões a respeito do conceito de comunidade nos anais da ABRAPSO, é interessante notar que faltam debates relativos a esse tema, o que parece comum ao próprio campo da PSC brasileira. Somente nos anais do IV Encontro encontramos alguma discussão sobre esse conceito, enquanto, nos outros, raríssimas vezes se via algum apontamento a respeito, apesar dos termos comunidade e comunitário(a) serem amplamente utilizados. A noção comunidade ou o adjetivo comunitário que tem designado esse campo carece de reflexão mais acurada, e não tem sido por esse caminho que a PSC se consolidou.

Apesar da raridade de discussões conceituais a respeito do termo comunidade, os anais da ABRAPSO fornecem dois sentidos para esse lugar-objeto da PSC. Um desses sentidos descreve a comunidade como um lugar de carência, onde o que se encontra é fome, violência, "toda espécie de demanda", "onde falta tudo", lugar de vulnerabilidade social e risco, vínculos familiares rompidos ou famílias 
desestruturadas, comportamentos agressivos, alcoolismo, "o lugar onde os indivíduos já estão comprometidos mentalmente", dificuldades afetivas e sociais e baixa autoestima, entre outros. Essas descrições apresentam um caráter eminentemente negativo, em que se privilegia dizer o que aquele lugar não tem ou o que tem de ruim.

Há, contudo, outro sentido atribuído a comunidade aparentemente contrário ao mencionado anteriormente. A comunidade, nesse caso, é concebida como lugar onde encontramos um forte potencial de luta e de solidariedade, onde os valores comunitários possuem em si um potencial transformador. A valorização ou o resgate dos próprios valores já existentes na comunidade seria a forma mais direta para incentivar a participação e a mudança social (Maciel, 2007; Mello e Souza, 2007).

\section{Considerações finais}

Este texto pretende contribuir para os debates realizados em torno do que temos denominado Psicologia social comunitária. Isso se realizou a partir da apresentação do campo, por meio do mapeamento de referenciais teóricos enunciados por seus representantes e do destaque de algumas questões ainda pouco abordadas pela PSC. Foi a partir, principalmente, dos anais da
ABRAPSO que foi possível chegar a algumas problematizações relevantes para esse debate. Três eixos principais nos orientaram: a discussão em torno da definição do campo e a busca por sua especificidade, o levantamento dos objetivos das intervenções e o debate sobre o conceito de comunidade.

Ao retomar seus aspectos históricos, percebemos como o discurso que busca as origens da PSC tende a dicotomizar duas vertentes em sua trajetória, que se expressam pela divisão entre uma PSC norte e outra latino-americana. Tal oposição tem se configurado como dispositivo de legitimação não apenas da PSC mas também da Psicologia social crítica de uma forma geral, em que os argumentos histórico-sociais fazem parte de seus pressupostos. O deslocamento dos locais instituídos de atuação dos psicólogos para a comunidade promovido pela PSC representou importante papel na produção de uma psicologia envolvida com as realidades locais. Esse movimento, contudo, tem demandado a produção de um arsenal conceitual que ainda está em elaboração.

A intenção, por fim, é que, a partir deste texto, tenham emergido questões que ponham em movimento o campo, levantando discussões relevantes para aqueles que pesquisam, refletem e colocam em ação a PSC cotidianamente. 


\section{Mariana Alves Gonçalves}

Mestranda do Programa de Pós-graduação em Psicologia da Universidade Federal do Rio de Janeiro, Rio de Janeiro - RJ - Brasil.

E-mail: maryzen18@hotmail.com

Francisco Teixeira Portugal

Doutor em Psicologia pela Pontifícia Universidade Católica do Rio de Janeiro. Professor adjunto do Departamento de Psicologia Social e do Programa de Pós-graduação em Psicologia da Universidade Federal do Rio de Janeiro, Rio de Janeiro - RJ - Brasil.

E-mail: fportugal@ufrj.br

Endereço para envio de correspondência:

Rua Marquês de Olinda, 64/103A, Botafogo, Rio de Janeiro - RJ - Brasil. CEP: 22251-040 
Associação Brasileira de Psicologia Social - ABRAPSO. (1990/1991). Anais do VI Encontro Mineiro de Psicologia Social. Psicologia \& Sociedade, 6(9), 1-206.

Associação Brasileira de Psicologia Social - ABRAPSO. (1995). Anais do VII Encontro Nacional ABRAPSO 15 anos: perspectivas. Fortaleza, CE: Autor.

Associação Brasileira de Psicologia Social - ABRAPSO. (2003) Anais do XII Encontro Nacional da ABRAPSO. Porto Alegre: Autor. Recuperado em 20 de junho de 2012, da ABRAPSO (Associação Brasileira de Psicologia Social): http://www. abrapso.org.br/siteprincipal/index.php?option =com_conten t $\&$ task $=$ category $\&$ sectionid $=8 \& i d=50 \&$ Itemid $=46$

Associação Brasileira de Psicologia Social - ABRAPSO. (2007). Anais do XIV Encontro Nacional da ABRAPSO. Rio de Janeiro: Autor. Recuperado em 20 de junho de 2012, da ABRAPSO (Associação Brasileira de Psicologia Social): http://www. abrapso.org.br/siteprincipal/anexos/AnaisXIVENA/conteudo/ full mode.htm

Associação Brasileira de Psicologia Social - ABRAPSO (2012). Apresentação. Recuperado em 10 maio, 2012, da ABRAPSO:http://www.abrapso.org.br/conteudo/view?ID $\mathrm{CONTEUDO}=503$.
Álvaro, J. L., \& Garrido, A. (2006). Psicologia social: perspectivas psicológicas e sociológicas. São Paulo: McGrawHill.

Amarante, P. (Org.). (1995). Loucos pela vida: a trajetória da reforma psiquiátrica no Brasil. Rio de Janeiro: Fiocruz.

Andery, A. A. (1989). Psicologia social e comunitária. Psicologia \& Sociedade, 4(7), 125-135.

Arendt, R. J. J. (1997). Psicologia comunitária: teoria e metodologia. Psicologia: Reflexão e Crítica, 10(1), 5-13.

Barros, R. B. (2007). Grupo: a afirmação de um simulacro. Porto Alegre: Sulina/Editora da UFGRS

Bock, A. M. B., \& Furtado, O. (2006). A psicologia no Brasil e suas relações com o marxismo. In A. M. Jacó-Vilela, A. A. L. Ferreira \& F. T. Portugal (Orgs.), História da psicologia. Rumos e percursos (pp. 503-514). Rio de Janeiro: NAU Editora.

Bock, A. M. B., Gonçalves, M. G. M., \& Furtado, O. (2007). Silvia Lane e o projeto do "compromisso social da psicologia". Psicologia \& Sociedade, 19(Esp. 2), 46-56.

Bomfim, E. M. (1989). Notas sobre a psicologia social e comunitária no Brasil. Psicologia \& Sociedade, 4(7), 42-46. 
Bomfim, E. M. (1989). O psicólogo na comunidade. Psicologia e Sociedade, 4(7), 119-124.

Bomfim, E. M., \& Mata Machado, M. N. (1988). Psicologia comunitária. Psicologia \& Sociedade, 3(4), 13-16.

Brandão, I. R. (1999). As bases epistemológicas da psicologia comunitária. In I. R. Brandão \& Z. A. C. Bomfim (Orgs.), Os jardins da psicologia comunitária (pp. 31-48). Fortaleza, CE: Pró-reitoria de extensão da UFC, ABRAPSO.

Campos, R. H. F. (1996). Introdução: a psicologia social comunitária. In R. H. F. Campos (Org.), Psicologia social comunitária: da solidariedade à autonomia (pp. 9-15, 12a ed.). Petrópolis, RJ: Vozes.

Carvalho, B. P., \& Souza, T. M. S. (2010). A "escola de São Paulo" de psicologia social: apontamentos históricos. Psicologia em Estudo, 15(4), 713-721.

Freitas, M. F. Q. (1988). O psicólogo e a comunidade: algumas questões. Psicologia \& Sociedade, 3(5), 74-85.

Freitas, M. F. Q. (1996). Psicologia na comunidade, psicologia da comunidade e psicologia (social) comunitária - práticas da psicologia em comunidades nas décadas de 60 a 90, no Brasil. In R. H. F. Campos (Org.), Psicologia social comunitária: da solidariedade à autonomia (12a ed.,pp. 54-80). Petrópolis, RJ: Vozes.

Freitas, M. F. Q. (2003). Dinâmica comunitária e práticas psicossociais: significados e avanços na perspectiva dos atore envolvidos. In Anais do XII Encontro Nacional da ABRAPSO. Porto Alegre: ABRAPSO.

Freitas, M. F. Q. (2010). Intervenção comunitária e as possibilidades de transformação social. In J. C. Sarriera (Org.), Psicologia comunitária: estudos atuais (3a ed., pp. 11-29, ). Porto Alegre: Sulina.

Caplan, G. (1980). Princípios de Psiquiatria preventiva. Rio de Janeiro: Zahar

D’Amorin, M. A. (1980). A psicologia comunitária: considerações teóricas e práticas. Arquivos Brasileiros de Psicologia, 32(3), 99-105.

Gallindo, L. C. (1981). A psicologia como agente de transformações sociais. Dissertação de mestrado. ISOP, Fundação Getúlio Vargas, Rio de Janeiro, RJ.

Góis, C. W. L. (1989). Pedra Branca: uma contribuição em psicologia comunitária. Psicologia \& Sociedade, 5(8), 95-118.

Góis, C. W. (1990). Pedra Branca: uma contribuição em Psicologia Comunitária. Psicologia \& Sociedade, 5(8), 95-118.

Góis, C. W. (2005). Psicologia comunitária: atividade consciência. Fortaleza, CE: Publicações Instituto Paulo Freire de Estudos Psicossociais.

Góis, C. W. de L. (2008). Saúde comunitária: pensar e fazer. São Paulo: Aderaldo \& Rothschild.

Jacó-Vilela, A. M. (2011). Associação Brasileira de Psicologia Social (ABRAPSO). In A. M. Jacó-Vilela (Org.), Dicionário Histórico de Instituições de Psicologia no Brasil (pp. 47-49). Rio de Janeiro: Imago/CFP.

Jacques, M. G. C., Strey, M. N., Bernardes, N. M. G., Guareschi, P. A., Carlos, S. A., \& Fonseca, T. M. G. (2003). Psicologia social contemporânea: livro-texto (8a ed.). Petrópolis, RJ: Vozes.

Lane, S. T. M., \& Codo, W. (Orgs.). (1984). Psicologia social. O homem em movimento. São Paulo, Brasiliense.

Lane, S. T. M. (1996). Histórico e fundamentos da psicologia comunitária no Brasil. In: R. H. F. Campos (Org.), Psicologia Comunitária: da solidariedade à autonomia (pp. 17-34). Petrópolis, RJ: Vozes.
Lastória, L. A. C. N. (1989). A psicologia na comunidade. Psicologia \& Sociedade, 75(7), 143-146.

Maciel, T. M. F. B. (2007). A psicologia social e o paradigma do desenvolvimento. In Anais do XIV Encontro Nacional da ABRAPSO. Rio de Janeiro: ABRAPSO. Recuperado em 20 de junho de 2012, da ABRAPSO (Associação Brasileira de Psicologia Social): http://www.abrapso.org.br/siteprincipal/ anexos/AnaisXIVENA/conteudo/html/mesa/3044_mesa_ resumo.htm

Martín-Baró, I. (1996). O papel do psicólogo. Estudos em Psicologia, 2(1), 7-27.

Martín-Baró, I. (2009). Desafios e perspectivas da psicologia latino-americana. In R. Guzzo \& F. Lacerda (Orgs.), Psicologia social para a América Latina: o resgate da psicologia da libertação. (pp. 199-220). Campinas, SP: Alínea.

Martín-Baró, I. (2009). Para uma psicologia da libertação. In R. Guzzo \& F. Lacerda (Orgs.), Psicologia social para a América Latina: o resgaste da psicologia da libertação (pp. 189-197). Campinas, SP: Alínea. (Trabalho original publicado na revista Boletin de Psicologia, 22, 1986).

Mello e Souza, C. (2003). Fundamentos da intervenção comunitária e sua relação com a realidade: contribuições da antropologia e dos estudos culturais In Anais do XII Encontro Nacional da ABRAPSO (s/n.). Rio de Janeiro: ABRAPSO. Recuperado em 20 de junho de 2012, da ABRAPSO (Associação Brasileira de Psicologia Social): http://abrapso. org.br/siteprincipal/index.php?option=com_content\&task= view\&id $=136 \&$ Itemid $=46$

Mello e Souza, C. (2007). Ações Territoriais da Rede de Comunidades Saudáveis do Rio de Janeiro. Bases para Políticas Públicas em Promoção da Saúde. In Anais do XIV Encontro Nacional da ABRAPSO. Rio de Janeiro: ABRAPSO. Recuperado em 20 de junho de 2012, da ABRAPSO (Associação Brasileira de Psicologia Social): http://www.abrapso.org.br/siteprincipal/ anexos/AnaisXIVENA/conteudo/html/mesa/3126_mesa_ resumo.htm

Montero, M. (2011). Introducción a la psicología comunitaria Desarrollo, conceptos y procesos (4a ed.). Buenos Aires: Paidós.

Nascimento, M. L. (2001). História do trabalho comunitário em psicologia. In A. M. Jacó-Vilela, A. C. Cerezzo \& H. C. Rodrigues, (Orgs.), Clio-Psyché hoje. Fazeres e dizeres psi na história do Brasil. Rio de Janeiro (pp. 33-42). Rio de Janeiro: Relume-Dumará / Faperj.

Nepomuceno, L. B., Ximenes, V. M., Cidade, E. C., Mendonça, F., \& Soares, C. A. (2008). Por uma psicologia comunitária como práxis de libertação. Psico, 39(4), 456-464.

Sawaia, B. B. (2007). Comunidade: a apropriação científica de um conceito tão antigo quanto a humanidade. In R. H. F. Campos (Org.), Psicologia social comunitária: da solidariedade à autonomia (12a ed., pp. 35-53). Petrópolis, RJ: Vozes.

Silva, M. V. (2007). Psicologia social comunitária e políticas públicas: provocações para um debate. In Anais do XIV Encontro Nacional da ABRAPSO. Rio de Janeiro: ABRAPSO. Recuperado em 20 de junho de 2012, da ABRAPSO (Associação Brasileira de Psicologia Social):http://www. abrapso.org.br/siteprincipal/anexos/AnaisXIVENA/conteudo/ $\mathrm{html} / \mathrm{mesa} / 3126$ mesa_resumo.htm

Yamamoto O., \& Oliveira, I. (2010). Política Social e Psicologia: Uma Trajetória de 25 Anos. Psicologia: Teoria e Pesquisa, 26(Esp.), 9-24. 